\title{
Prevalence of Nicotine Dependence Among Industrial Workers in Myanmar
}

\author{
Myo Zin Oo ${ }^{1 *}$, Alessio Panza ${ }^{1} \&$ Sathirakorn Pongpanich ${ }^{1 *}$ \\ ${ }^{1}$ College of Public Health Sciences, Chulalongkorn University, Bangkok, Thailand \\ *Correspondence: Sathirakorn Pongpanich and Myo Zin Oo, College of Public Health Sciences, Chulalongkorn \\ University, Bangkok, 10330, Thailand. E-mail: sathirakorn.p@chula.ac.th; dr.myozinoo@gmail.com
}

Received: January 18, 2019 Accepted: February 17, 2019 Online Published: February 27, 2019

doi:10.5539/gjhs.v11n3p122 URL: https://doi.org/10.5539/gjhs.v11n3p122

\begin{abstract}
Smoking is one of the major public health concerns and it is harmful to people's health status. This cross sectional survey was conducted to study the Nicotine dependence among industrial workers in Myanmar. Mandalay city was purposively selected where the second largest industrial zone is situated. A total of two hundred and ninety two industrial workers aged sixteen years old and above participated. Data collection was done by using an interviewer administered questionnaire. Data analysis was done by using SPSS version 23 and descriptive findings were interpreted as frequency and percentage, and the chi-squared test was used to find the association of nicotine dependence. The significance level of all statistical tests was determined with the $p$ value $<0.05$. All of the respondents were male $(100 \%)$ and the mean age of the respondents was 30.7 . About $75 \%$ of the industrial workers showed low and very low dependence from the nicotine while the rest $25 \%$ showed medium to very high dependence. There was a statistically significance association between age $(\mathrm{p}<0.001)$, marital status $(\mathrm{p}=0.031)$, education status $(p<0.001)$, income $(p<0.001)$, age at first cigarette smoked $(p<0.001)$ and number of years cigarette smoked $(\mathrm{p}<0.015)$ and nicotine dependence. Further studies with similar setting are recommended to conduct on nicotine dependence and its correlation among the industrial workers in Myanmar, and the government authority should plan and conduct the effective intervention on health education and awareness program about smoking and nicotine dependence.
\end{abstract}

Keywords: industrial workers, Myanmar, nicotine dependence

\section{Introduction}

Smoking cigarette is one of the leading cause of premature mortality and preventable cause of disease and death (World Health Organization [WHO], 2013). There are more than 1.1 billion people who smoke tobacco in low and middle-income countries, and more than 7 million people are killed by tobacco each year which is half of its user (WHO, 2018). In South East Asian (ASEAN) regions, there are about 122.4 million adult people are smokers and it is highest in Indonesia (53.3\%) and Myanmar is the fifth country with 5.1\% (Southeast Asia Tobacco Control Alliance, 2016). According to the Myanmar National Survey, the prevalence of current smoking of both sexes was $26.1 \%$ with $43.8 \%$ in men and $8.4 \%$ in women (Ministry of Health [MOH], 2014a). Smoking is the second leading cause of Disability Adjusted Life Years (DALYs) in Myanmar and it causes death for approximately 0.2 million citizens of age 30 years and above (WHO, 2012).

Nicotine dependence which is also called tobacco dependence is the addiction to tobacco products which is caused by nicotine: a colorless, poisonous alkaloid from the tobacco plant. When one smokes, nicotine releases physical and mood changes that affect the brain which can make the smokers pleased and leads to the dependence (Mayo Clinic, 2018).

Although the smoking prevalence is decreasing in many countries, inconsistency among the occupation group is still present that is increasing of smoking among the workers. Smoking can lead the workers to reduce productivity and unemployment due to chronic diseases and finally to death. In a previous cross-sectional study among 288 , 813 US workers on smoking abstinence, blue collar workers smoke more than white collar workers (Fagan, Shavers, Lawrence, Gibson, \& O'Connel, 2007). As there is a large number of people, workplaces are the potential place to promote the smoking cessation program and to reach many other people beyond them (Gulsen, Mehtap, \& Leyla, 2006). Although there are limited studies in Myanmar about the prevalence of smoking tobacco, there are no studies regarding the nicotine dependence among industrial workers. 
The objective of this study was to assess the prevalence and correlation of nicotine dependence among industrial workers in Myanmar.

\section{Methods}

This cross sectional study was conducted in Mandalay industrial zone, Mandalay city, Myanmar. Mandalay is located in the central part of Myanmar and has the second largest industrial zone with a total of 794 industries. The required sample size calculated with the Cochran formula was 292 industrial current smokers. An interviewer administered questionnaire was used. The "Fagerstrom Test for Nicotine Dependence" was used to assess the Nicotine dependence which consisted of a total of 6 questions, and it was categorized into 5 dependency groups; very low dependence ( $0-2$ score), low dependence (3-4 score), medium dependence ( 5 scores), high dependence (6-7 scores), and very high dependence (8-10 scores) (Mahajan et al., 2016). The independent variables studied for possible associations were (i) socio-demographic characteristics (age, marital status, education status, and monthly income), (ii) smoking history (age at first cigarette smoking, number of years cigarette smoked, number of cigarettes smoked per week). Descriptive findings are shown as frequency and percentage, Chi-squared test was used to find associations. Data analysis was conducted by using SPSS version 23 and the significance level of all statistical tests was determined with the $p$ value $<0.05$. The ethical approval for this study was taken from RECCU (The Research Ethics Review Committee For Research Involving Human Research Participants, Health Sciences Group, Chulalongkorn University), Thailand.

\section{Results}

Among 292 smoked industrial workers, all of the respondents were male (100\%). About half (49\%) of the respondents were in the age group of 16 to 25 years with the mean age of 30.7 and $54.1 \%$ of the respondents were single-never married. Among all of the respondents, two third had high education (38.7\% high school, and $39.4 \%$ university education respectively). About $83.6 \%$ of the respondents had monthly income more than 150,000 Kyats (97 USD; 1USD equivalent to 1540 MMK, assessed on $7^{\text {th }}$ January 2019) (Central Bank of Myanmar, 2019).

The mean age of start smoking cigarette was 18 years and about $21.6 \%$ of the respondents started cigarette smoking before 15. The mean number of year cigarette smoked (duration of cigarette smoked from the first time of smoking to current answered time) was 12.5 and the number of cigarettes smoked per week was 22.4.

Table 1 shows the level of Nicotine Dependence among the respondents. About $25 \%$ of the respondents showed medium to very high nicotine dependence while the rest (75\%) showed low and very low dependence.

Table 1. Level of Nicotine Dependence of the respondents $(n=292)$

\begin{tabular}{lll}
\hline Nicotine Dependence & Frequency & Percentage \\
& $(\mathrm{n})$ & 31.8 \\
\hline Very Low Dependence & 93 & 43.2 \\
Low Dependence & 126 & 5.8 \\
Medium Dependence & 17 & 17.8 \\
High Dependence & 52 & 1.4 \\
Very High Dependence & 4 & \\
\hline
\end{tabular}


Table 2. Frequency and percentage of Fagerstrom test for Nicotine Dependence

\begin{tabular}{|c|c|c|}
\hline Nicotine Dependence & Frequency (n) & Percentage (\%) \\
\hline \multicolumn{3}{|c|}{ How soon after waking do you smoke your first cigarette? } \\
\hline Within $5 \mathrm{~min}$ & 124 & 42.5 \\
\hline $5-30 \mathrm{~min}$ & 109 & 37.3 \\
\hline $31-60 \mathrm{~min}$ & 59 & 20.2 \\
\hline \multicolumn{3}{|c|}{ Do you find it difficult to refrain from smoking in places where it is forbidden? } \\
\hline Yes & 73 & 25.0 \\
\hline No & 219 & 75.0 \\
\hline \multicolumn{3}{|c|}{ Which cigarette would you hate to give up? } \\
\hline The first in the morning & 61 & 20.9 \\
\hline Any other & 231 & 79.1 \\
\hline \multicolumn{3}{|c|}{ How many cigarettes a day do you smoke? } \\
\hline 10 or less & 234 & 80.1 \\
\hline $11-20$ & 51 & 17.5 \\
\hline $21-30$ & 7 & 2.4 \\
\hline 31 or more & 0 & 0.0 \\
\hline \multicolumn{3}{|c|}{ Do you smoke more frequently in the morning? } \\
\hline Yes & 125 & 42.8 \\
\hline No & 167 & 57.2 \\
\hline \multicolumn{3}{|c|}{ Do you smoke even if you are sick in bed most of the day? } \\
\hline Yes & 41 & 14.0 \\
\hline No & 251 & 86.0 \\
\hline
\end{tabular}

There was a statistically significant association between age, marital status, education status, monthly income and nicotine dependence (Table 3). Nearly half of the respondents (43.2\%) in the age group of 36-45 showed a prevalence of high to very high nicotine dependence $(\mathrm{p}<0.001)$. About $80 \%$ of both single-never married and married respondents had very low to medium nicotine dependence and showed higher dependence in married respondents $(19.0 \%)$ than single-never married $(16.4 \%)(\mathrm{p}=0.031)$. Regarding education status, about $41.6 \%$ of the respondents who had finished "high school" were high nicotine dependence $(\mathrm{p}<0.001)$ and income within “150001 - 180000 kyats (USD 97.4 - 116.9)" showed medium to very high dependence of nicotine $(10.8 \%, 24.2 \%$, and $2.5 \%)(\mathrm{p}<0.001)$.

Regarding smoking history, age at first cigarette smoked and the number of years cigarette smoked had a significant association with nicotine dependence. About $44.4 \%$ of respondents who started smoking their first cigarette at the age of under 15 showed medium to high nicotine dependence $(p<0.001)$. About $30.4 \%$ of respondents showed high to very high dependence if they had more than 20 years of smoking history $(p<0.015)$. Among respondents, 36.7\% who smoked 31 - 45 cigarettes per week showed high and very high nicotine dependence. 
Table 3. Association between Socio-demographic characteristics, Smoking History and Nicotine Dependence $(\mathrm{n}=292)$

\begin{tabular}{|c|c|c|c|c|c|c|c|}
\hline \multirow[b]{2}{*}{ Variables } & \multicolumn{5}{|c|}{ Nicotine Dependence n (\%) } & \multirow[b]{2}{*}{$\mathbf{x}^{2}$} & \multirow[b]{2}{*}{ p-value } \\
\hline & $\begin{array}{l}\text { VLD } \\
\text { n (\%) }\end{array}$ & $\begin{array}{l}\text { LD } \\
\text { n (\%) }\end{array}$ & $\begin{array}{l}\text { MD } \\
\text { n (\%) }\end{array}$ & $\begin{array}{l}\text { HD } \\
\text { n (\%) }\end{array}$ & $\begin{array}{l}\text { VHD } \\
\text { n (\%) }\end{array}$ & & \\
\hline \multicolumn{8}{|l|}{ Age (years) } \\
\hline $16-25$ & $\begin{array}{l}31 \\
(31.6)\end{array}$ & $\begin{array}{l}37 \\
(37.8)\end{array}$ & $\begin{array}{l}13 \\
(13.3)\end{array}$ & $\begin{array}{l}15 \\
(15.3)\end{array}$ & $\begin{array}{l}2 \\
(2.0)\end{array}$ & & \\
\hline $26-35$ & $\begin{array}{l}48 \\
(39.3)\end{array}$ & $\begin{array}{l}53 \\
(43.4)\end{array}$ & $\begin{array}{l}4 \\
(3.3)\end{array}$ & $\begin{array}{l}16 \\
(13.1)\end{array}$ & $\begin{array}{l}1 \\
(0.8)\end{array}$ & & \\
\hline $36-45$ & $\begin{array}{l}8 \\
(18.2)\end{array}$ & $\begin{array}{l}17 \\
(38.6)\end{array}$ & $\begin{array}{l}0 \\
(0.0)\end{array}$ & $\begin{array}{l}18 \\
(40.9)\end{array}$ & $\begin{array}{l}1 \\
(2.3)\end{array}$ & 49.446 & $<0.001 *$ \\
\hline $46-55$ & $\begin{array}{l}6 \\
(40.0)\end{array}$ & $\begin{array}{l}7 \\
(46.7)\end{array}$ & $\begin{array}{l}0 \\
(0.0)\end{array}$ & $\begin{array}{l}2 \\
(13.3)\end{array}$ & $\begin{array}{l}0 \\
(0.0)\end{array}$ & & \\
\hline$>56$ & $\begin{array}{l}0 \\
(0.0)\end{array}$ & $\begin{array}{l}12 \\
(92.3)\end{array}$ & $\begin{array}{l}0 \\
(0.0)\end{array}$ & $\begin{array}{l}1 \\
(7.7)\end{array}$ & $\begin{array}{l}0 \\
(0.0)\end{array}$ & & \\
\hline \multicolumn{8}{|l|}{ Marital Status } \\
\hline Single never-married & $\begin{array}{l}37 \\
(27.6)\end{array}$ & $\begin{array}{l}59 \\
(44.0)\end{array}$ & $\begin{array}{l}12 \\
(9.0)\end{array}$ & $\begin{array}{l}22 \\
(16.4)\end{array}$ & $\begin{array}{l}4 \\
(3.0)\end{array}$ & 10.602 & $0.031^{*}$ \\
\hline Married & $\begin{array}{l}56 \\
(35.4)\end{array}$ & $\begin{array}{l}67 \\
(42.4)\end{array}$ & $\begin{array}{l}5 \\
(3.2)\end{array}$ & $\begin{array}{l}30 \\
(19.0)\end{array}$ & $\begin{array}{l}0 \\
(0.0)\end{array}$ & & \\
\hline \multicolumn{8}{|l|}{ Education Status } \\
\hline Primary school (1-4) & $\begin{array}{l}5 \\
(18.5)\end{array}$ & $\begin{array}{l}16 \\
(59.3)\end{array}$ & $\begin{array}{l}0 \\
(0.0)\end{array}$ & $\begin{array}{l}6 \\
(22.2)\end{array}$ & $\begin{array}{l}0 \\
(0.0)\end{array}$ & & \\
\hline Middle school (5-8) & $\begin{array}{l}9 \\
(24.3)\end{array}$ & $\begin{array}{l}25 \\
(67.6)\end{array}$ & $\begin{array}{l}3 \\
(8.1)\end{array}$ & $\begin{array}{l}0 \\
(0.0)\end{array}$ & $\begin{array}{l}0 \\
(0.0)\end{array}$ & 85.409 & $<0.001^{*}$ \\
\hline High school (9-10) & $\begin{array}{l}39 \\
(34.5)\end{array}$ & $\begin{array}{l}24 \\
(21.2)\end{array}$ & $\begin{array}{l}3 \\
(2.7)\end{array}$ & $\begin{array}{l}43 \\
(38.1)\end{array}$ & $\begin{array}{l}4 \\
(3.5)\end{array}$ & & \\
\hline University education & $\begin{array}{l}40 \\
(34.8)\end{array}$ & $\begin{array}{l}61 \\
(53.0)\end{array}$ & $\begin{array}{l}11 \\
(9.6)\end{array}$ & $\begin{array}{l}3 \\
(2.6)\end{array}$ & $\begin{array}{l}0 \\
(0.0)\end{array}$ & & \\
\hline \multicolumn{8}{|l|}{ Monthly Income } \\
\hline$<150,000$ & $\begin{array}{l}20 \\
(41.7)\end{array}$ & $\begin{array}{l}28 \\
(58.3)\end{array}$ & $\begin{array}{l}0 \\
(0.0)\end{array}$ & $\begin{array}{l}0 \\
(0.0)\end{array}$ & $\begin{array}{l}0 \\
(0.0)\end{array}$ & & \\
\hline $150,001-180,000$ & $\begin{array}{l}45 \\
(28.7)\end{array}$ & $\begin{array}{l}53 \\
(33.8)\end{array}$ & $\begin{array}{l}17 \\
(10.8)\end{array}$ & $\begin{array}{l}38 \\
(24.2)\end{array}$ & $\begin{array}{l}4 \\
(2.5)\end{array}$ & 39.568 & $<0.001^{*}$ \\
\hline$>180,001$ & $\begin{array}{l}28 \\
(32.2)\end{array}$ & $\begin{array}{l}45 \\
(51.7)\end{array}$ & $\begin{array}{l}0 \\
(0.0)\end{array}$ & $\begin{array}{l}14 \\
(16.1)\end{array}$ & $\begin{array}{l}0 \\
(0.0)\end{array}$ & & \\
\hline \multicolumn{8}{|c|}{ Age at first cigarette smoked } \\
\hline$<15$ & $\begin{array}{l}9 \\
(14.3)\end{array}$ & $\begin{array}{l}26 \\
(41.3)\end{array}$ & $\begin{array}{l}9 \\
(14.3)\end{array}$ & $\begin{array}{l}15 \\
(23.8)\end{array}$ & $\begin{array}{l}4 \\
(6.3)\end{array}$ & 37.924 & $<0.001 *$ \\
\hline $16-25$ & $\begin{array}{l}84 \\
(37.2)\end{array}$ & $\begin{array}{l}97 \\
(42.9)\end{array}$ & $\begin{array}{l}8 \\
(3.5)\end{array}$ & $\begin{array}{l}37 \\
(16.4)\end{array}$ & $\begin{array}{l}0 \\
(0.0)\end{array}$ & & \\
\hline
\end{tabular}




\begin{tabular}{|c|c|c|c|c|c|c|c|}
\hline$>26$ & $\begin{array}{l}0 \\
(0.0)\end{array}$ & $\begin{array}{l}3 \\
(100.0)\end{array}$ & $\begin{array}{l}0 \\
(0.0)\end{array}$ & $\begin{array}{l}0 \\
(0.0)\end{array}$ & $\begin{array}{l}0 \\
(0.0)\end{array}$ & & \\
\hline \multicolumn{8}{|c|}{ Number of years cigarette smoked } \\
\hline $1-3$ & $\begin{array}{l}11 \\
(36.5)\end{array}$ & $\begin{array}{l}15 \\
(98.4)\end{array}$ & $\begin{array}{l}5 \\
(16.1)\end{array}$ & $\begin{array}{l}0 \\
(0.0)\end{array}$ & $\begin{array}{l}0 \\
(0.0)\end{array}$ & & \\
\hline $4-11$ & $\begin{array}{l}46 \\
(36.2)\end{array}$ & $\begin{array}{l}49 \\
(38.6)\end{array}$ & $\begin{array}{l}10 \\
(7.9)\end{array}$ & $\begin{array}{l}20 \\
(15.7)\end{array}$ & $\begin{array}{l}2 \\
(1.6)\end{array}$ & 25.035 & $0.015^{*}$ \\
\hline $12-19$ & $\begin{array}{l}23 \\
(29.5)\end{array}$ & $\begin{array}{l}36 \\
(46.2)\end{array}$ & $\begin{array}{l}2 \\
(2.6)\end{array}$ & $\begin{array}{l}16 \\
(20.5)\end{array}$ & $\begin{array}{l}1 \\
(1.3)\end{array}$ & & \\
\hline$>20$ & $\begin{array}{l}13 \\
(23.2)\end{array}$ & $\begin{array}{l}26 \\
(46.4)\end{array}$ & $\begin{array}{l}0 \\
(0.0)\end{array}$ & $\begin{array}{l}16 \\
(28.6)\end{array}$ & $\begin{array}{l}1 \\
(1.8)\end{array}$ & & \\
\hline \multicolumn{8}{|c|}{ Number of cigarette smoked per week } \\
\hline$<15$ & $\begin{array}{l}39 \\
(36.1)\end{array}$ & $\begin{array}{l}46 \\
(42.6)\end{array}$ & $\begin{array}{l}8 \\
(7.4)\end{array}$ & $\begin{array}{l}14 \\
(13.0)\end{array}$ & $\begin{array}{l}1 \\
(0.9)\end{array}$ & & \\
\hline $16-30$ & $\begin{array}{l}41 \\
(27.9)\end{array}$ & $\begin{array}{l}68 \\
(46.3)\end{array}$ & $\begin{array}{l}8 \\
(5.4)\end{array}$ & $\begin{array}{l}29 \\
(19.7)\end{array}$ & $\begin{array}{l}1 \\
(0.7)\end{array}$ & 17.783 & 0.122 \\
\hline $31-45$ & $\begin{array}{l}10 \\
(33.3)\end{array}$ & $\begin{array}{l}8 \\
(26.7)\end{array}$ & $\begin{array}{l}1 \\
(3.3)\end{array}$ & $\begin{array}{l}9 \\
(30.0)\end{array}$ & $\begin{array}{l}2 \\
(6.7)\end{array}$ & & \\
\hline$>46$ & $\begin{array}{l}3 \\
(42.9)\end{array}$ & $\begin{array}{l}4 \\
(57.1)\end{array}$ & $\begin{array}{l}0 \\
(0.0)\end{array}$ & $\begin{array}{l}0 \\
(0.0)\end{array}$ & $\begin{array}{l}0 \\
(0.0)\end{array}$ & & \\
\hline
\end{tabular}

* Significant Level $(\mathrm{p}<0.05)$.

Abbreviations: $\mathrm{VLD}=$ Very Low Dependence, $\mathrm{LD}=$ Low Dependence, $\mathrm{MD}=$ Medium Dependence, HD= High Dependence, $\mathrm{VHD}=$ Very High Dependence.

\section{Discussion}

This present study stated that $43.2 \%$ of the respondents had low nicotine dependence which is consistent with the findings of the community based study which was conducted among 572 urban slums in India (Saha, Islam, Paul, $\&$ Som, 2017). This present study found that only $1.4 \%$ of the participants had very high nicotine dependence which is consistence with the result of community based survey from Angola which was conducted among 2,472 respondents on tobacco consumption and nicotine dependence (Pedro, Brito, \& Barros, 2017). These findings can be due to the participation of younger age group including fewer years of cigarette smoking and lesser number of cigarettes smoked per week which leads to low nicotine dependence.

In the cross sectional study by Manimunda et al. (2012) which was conducted in India among 18,000 individuals older age group, low-socio-economic status, married individuals have a high level of nicotine dependence but this present study found that respondents in the younger age group, single-never married and had income, had more salary than other respondents, were more likely to smoke cigarettes and showed medium to high dependence although there were more in low and very low nicotine dependence than medium, high and very high dependence groups (Manimunda et al., 2012). The difference between our finding and the Manimunda study may be due to the younger age, peer pressure, occupational stress, and freedom from the family of their respondents.

There was a high proportion (30.1\%) of high and very high dependence among the respondents who started their first cigarette below 15 years of their age than other age groups, it was consistent with the findings from the study by Saha et al. (2017) which was conducted among 572 urban slums in India and by Roberts et al. (2013): a cross sectional study among men and women with the aged 18 years and above from nine countries (Roberts et al., 2013; Saha et al., 2017) and this is probably due to cigarettes being easily accessible and available among younger age group and they need early tobacco free years through banning and by regulations to control not selling cigarettes to this younger age group.

Being the member of WHO FCTC (Framework and Convention on Tobacco control) since 2003, Myanmar has 
started the implementation of six policies; MPOWER (monitoring tobacco use and prevention policies, protecting people from tobacco smoke, offering help to quit tobacco use, warning about the dangers of tobacco, enforcing bans on tobacco advertising, promotion and sponsorship, raising tobacco taxes) (MOH, 2014b).

\section{Conclusion}

To our knowledge, the strength of this present study is the first study on the prevalence of nicotine dependence among industrial workers in Mandalay, Myanmar. A national survey or another similar setting of the study on the prevalence of nicotine dependence and its correlation among industrial workers in Myanmar is recommended. Although there were low nicotine dependence, younger age group and young age at first cigarette smoking was found in this study. Therefore, Myanmar should put more effort on the implementation of banning and selling cigarettes to people less than 18 years of age. Regarding the awareness of smoking and nicotine dependence, a community based health education program should be planned and conducted by the government authority with the collaboration of local health authorities through workplaces and schools to reach young age groups. This health education program on smoking and nicotine dependence should include the risk of several health problems, severity, and effects of nicotine dependence. Not only conducting health education programs, but also the rehabilitation center or health services for those who want to quit smoking including counseling process should be developed.

\section{Funding}

This research is supported by the $90^{\text {th }}$ year Anniversary of Chulalongkorn University, Rachadapisek Somphot Fund.

\section{Acknowledgements}

We would like to show our gratitude to the industrial workers who had participated in this study and the concerned supervisors, higher level staffs and board of directors from the participated industry including the committee members of the Industrial zone.

\section{Competing Interests Statement}

The Authors declare that they have no conflicts of interest.

\section{References}

Central Bank of Myanmar. (2019). Reference Exchange Rate. Retrieved January 7, 2019, from https://forex.cbm.g ov.mm/index.php/fxrate

Fagan, P., Shavers, V., Lawrence, D., Gibson, J., \& O'Connel, M. (2007). Employment characteristics and socioeconomic factors associated with disparities in smoking abstinence and former smoking among U.S. workers. Journal of Health Care for the Poor and Underserved, 18(4), 52-72. https://doi.org/10.1353/hpu.2007.0119

Gulsen, G., Mehtap, I., \& Leyla, K. (2006). The Effectiveness of an education program on stages of smoking behavior for workers at a factory in Turkey. Industrial Health, 45(2), 232-236. https://doi.org/10.2486/indhealth.45.232

Mahajan, R., Solanki, J., Kurdekar, R. S., Gupta, S., Modh, A., \& Yadav, O. (2016). Educating the handicraft factory workers about tobacco cessation and to assess its effectiveness by motivational interviewing: An Intervention study. Journal of Experimental Therapeutics and Oncology, 12(1), 43-49. Retrieved from https://www.ncbi.nlm.nih.gov/pubmed/28472563

Manimunda, P. S., Benegal, V., Sugunan, A. P., Jeemon, P., Balakrishna, N., Thennarusu, K., ... Pesala, K. S. (2012). Tobacco use and nicotine dependency in a cross-sectional representative sample of 18,018 individuals in Andaman and Nicobar Islands, India. BMC Public Health, 12(1), 515. https://doi.org/10.1186/1471-2458-12-515

Mayo Clinic. (2018). Nicotine Dependence: Symptoms \& Causes. Retrieved December 20, 2018, from https://www. mayoclinic.org/ diseases-conditions/nicotine-dependence/symptoms-causes/syc-20351584

Ministry of Health [MOH]. (2014a). Report on National Survey on Diabetes mellitus and risk factors for non-communicable diseases (NCDs) in Myanmar. Ministry of Health. Retrieved from https://www.medbox. $\mathrm{org} /$ myanmar/report-on-national-survey-of-diabetes-mellitus-and-risk-factors-for-non-communicable-diseas es-ncds-in-myanmar/preview?q=

Ministry of Health [MOH]. (2014b). Health in Myanmar: Tobacco Control Measures. Ministry of Health. 
Retrieved from http://mohs.gov.mm/Main/content/publication/health-in-myanmar-2014

Pedro, J. M., Brito, M., \& Barros, H. (2017). Tobacco consumption and nicotine dependence in Bengo Province, Angola: A community-based study. PLOS One, 12(11), e0188586. https://doi.org/10.1371/journal.pone. 0188586

Roberts, B., Gilmore, A., Stickley, A., Kizilova, K., Prohoda, V., Rotman, D., ... \& Mckee, M. (2013). Prevalence and psychosocial determinants of nicotine dependence in nine countries of the former Soviet Union. Nicotine \& Tobacco Research, 15(1), 271-276. https://doi.org/10.1093/ntr/nts100

Saha, I., Islam, K., Paul, B., \& Som, T. K. (2017). Nicotine dependence and its correlates among the adult tobacco users in a slum of Burdwan district, West Bengal, India. Journal of Family Medicine and Primary Care, 6(4), 813-818. https://doi.org/10.4103/jfmpc.jfmpc_42_17

Southeast Asia Tobacco Control Alliance. (2016). The Tobacco Control Atlas: ASEAN region. Retrieved from https://seatca.org/dmdocuments/SEATCA\%20Tobacco\%20Control \%20Atlas\%20ASEAN\%20Region\%204 th \%20Ed\%20Sept\%202018.pdf

World Health Organization [WHO]. (2012). Global Report: Mortality attributable to tobacco. World Health Organization. Retrieved from https://apps.who.int/iris/bitstream/handle/ 10665/44815/9789241564434_ eng.pdf;jsessionid=4FB7513D47F46FD57329D992446CA61C? sequence $=1$

World Health Organization [WHO]. (2013). WHO Report on the Global Tobacco Epidemic 2013: Enforcing bans on tobacco advertising, promotion and sponsorship. World Health Organization. Retrieved from https://apps. who.int/iris/bitstream/handle/10665/85380/9789241505871_eng.pdf?sequence=1

World Health Organization [WHO]. (2018). Tobacco: Key Facts. World Health Organization. Retrieved December 24, 2018, from https://www.who.int/news-room/fact-sheets/detail/ tobacco

\section{Copyrights}

Copyright for this article is retained by the author(s), with first publication rights granted to the journal.

This is an open-access article distributed under the terms and conditions of the Creative Commons Attribution license (http://creativecommons.org/licenses/by/4.0/). 